\title{
Erratum to: White Collar Crime and Risk
}

Nic Ryder

\section{Erratum to:}

N. Ryder (ed.), White Collar Crime and Risk, https://doi.org/10.1057/978-1-137-47384-4

The book was inadvertently published with errors including: Viri Chauhan was missing as an author in Chapter 3, Viri Chauhan's biography was missing in the Notes on Contributors, and the acknowledgement text was missing from Chapter 6. All of these errors have been updated in the corresponding chapters.

The updated online version of these chapters can be found at https://doi.org/10.1057/978-1-137-47384-4 https://doi.org/10.1057/978-1-137-47384-4_3 https://doi.org/10.1057/978-1-137-47384-4_6 